\title{
TEACHING SUMMARIZING AND PARAPHRASING SKILLS IN A FOREIGN LANGUAGE CLASSROOM
}

\author{
Papoyan A., Ph. D Associate Professor, VSU, Vanadzor, Armenia
}

DOI: https://doi.org/10.31435/rsglobal_conf/30082021/7647

\begin{abstract}
Paraphrasing and summarizing are powerful skills that everyone should develop while learning a foreign language. These two tools are the main clues for integrating the sources into the papers. Paraphrasing and summarizing are very useful as they allow to convey other's ideas in one's speech without cluttering up the paragraphs with quotation marks. It is important to be able to summarize and paraphrase correctly to effectively integrate the research into the paper without any plagiarism.

By paraphrasing and summarizing the writer shows a full understanding of the topic, identifies the most important information and explains it using his way of outlook.

The article tries to highlight the main characteristic features of paraphrasing and summarizing skills, suggests some ways how to develop them and tries to find out the existing differences between them.

Keywords: Summarizing, Paraphrasing, Writing skills, paraphrased text, summarized text, practical activities.
\end{abstract}

Paraphrasing and summarizing are considered to be important functional skills. However, developing these skills is not a one-day procedure that can be attained at once. It requires hard work, analytical and critical way of thinking.

While learning how to use these skills as important tools, it is also very essential to understand the difference existing between paraphrasing and summarizing.

The article suggests some techniques and strategies improve paraphrasing and summarizing skills drawing parallels between them.

Paraphrasing is the process of restating information in a different way keeping close to the original meaning. Thus, while paraphrasing students become aware of the fact that we can convey one and the same idea in different ways which may also improve FL learner's speaking, writing, reading and listening skills. Therefore, paraphrasing may be viewed not only as an isolated skill, but also as a means to master a foreign language. With paraphrasing it becomes obvious that the student understands the core idea of the source he/she is referring to. It can be also helpful when complex information needs to be simplified. According to Publication Manual of the American Psychological Association (10) paraphrasing is considered as a model of 'adaptation' which is referred to as modifying the material in a way that it may suit a new purpose making the reader observe the text in a new way.

Paraphrasing is very important in situations when one needs to quote someone but can not remember the person's statement word for word. We also need to paraphrase because using another author's exact words (when not directly quoted) is plagiarism or academic dishonesty.

While paraphrasing we should maintain the original meaning but we also have to say it in our own words, so that it should be clearer and much more easily understood than the original statement. But at the same time, it should be properly cited.

While paraphrasing the following scheme should be followed: 


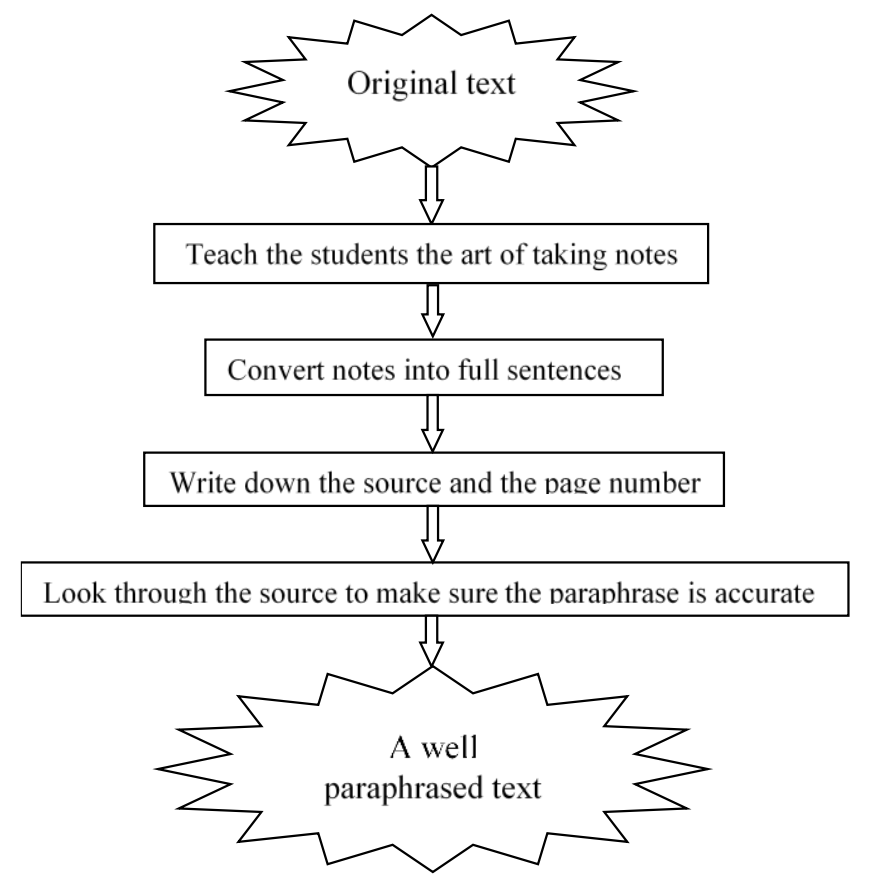

It doesn't take long hours to develop paraphrasing skills. It can be done regularly in not more than 10 minutes at every lesson. Here are some practical activities to develop paraphrasing skills.

1. The first student reads (listens to) the passage. Then he/she retells what he /she has understood from the passage to the second student. The second one paraphrases and tells the third student what he has understood. Several students do the same action and in the end we will have a totally new paraphrased version of the initial text. The difficulty here is to be cautious not to diverge from the model that has been given and not to develop a different concept. The process should be controlled by the teacher who should follow the whole process of the paraphrasing exercise.

2. The teacher shows the students a certain range of pictures to make a story. The story underlying the picture should be clear and understandable. The students take notes and write down their stories based on the pictures. Then they read them out. At the beginning stage the students may be given a plan and some synonymous words that will help them to create the text in a better way.

3. An interesting and useful way of developing paraphrasing skills is to let the students explain to the mates what they have understood/learnt from that lesson at the very end of it. Firstly, this will allow the student to show his or her own way of expressing what has been learnt. Then, it can give a chance to the others to listen to the same thing through a simpler explanation. So not only they hear it once again but they hear it in a different and simpler way. This activity may serve as a feedback too, which should be very useful for the teacher as well.

Summarizing is a concise overview of the most important points from the passage. Summarizing is a very useful tool that a good communicator should have. A good summary shows that the person can understand and highlight the key ideas of the text. There are different areas where summarizing skills are highly appreciated since it teaches how to read, perceive information, regroup it and apply it to a new situation. Summarizing is said to be like mining for gold: it helps to find out the most important key details and main points in each paragraph [14].

Thus, summarizing creates a strong comprehension of the complex material.

In famous writing text 'Fit to Print', Buckley defines summarizing as reducing the size of the original text nearly three or four times, clearly expressing the author's thoughts and retaining the main ideas [6]. In 'A Canadian Writer's reference', the author confirms that summarizing is the work's thesis and the most important ideas described "simply, briefly and accurately" [1].

Summarization is one of the most underused teaching techniques nowadays, yet research has shown that it yields some of the greatest leaps in comprehension and long term retention of the information. Robert Marzano, Debra Pickering, and Jane Pollock [11] cite extensive research studies in their book, Classroom Instruction That Works: Research-Based Strategies for Increasing Student Achievement, to prove that summarization is among the top nine most effective teaching strategies in the history of education. 
Summaries vary in degree of consideration. The degree mostly depends on the information and what the planned use of summary is. Some summaries reduce the material to one fourth of the original (which is the classical way), the others might condense to a tenth of the original. Generally, the longer the original, the more condensed the summary. (3)

The main points that students must be taught while developing summarizing skills are:

- how to identify salient information,

- how to structure that information for successful application.

Summarizing is an academic method of deleting, substituting and keeping information. [11]

While summarizing the following key steps should be taken into consideration:

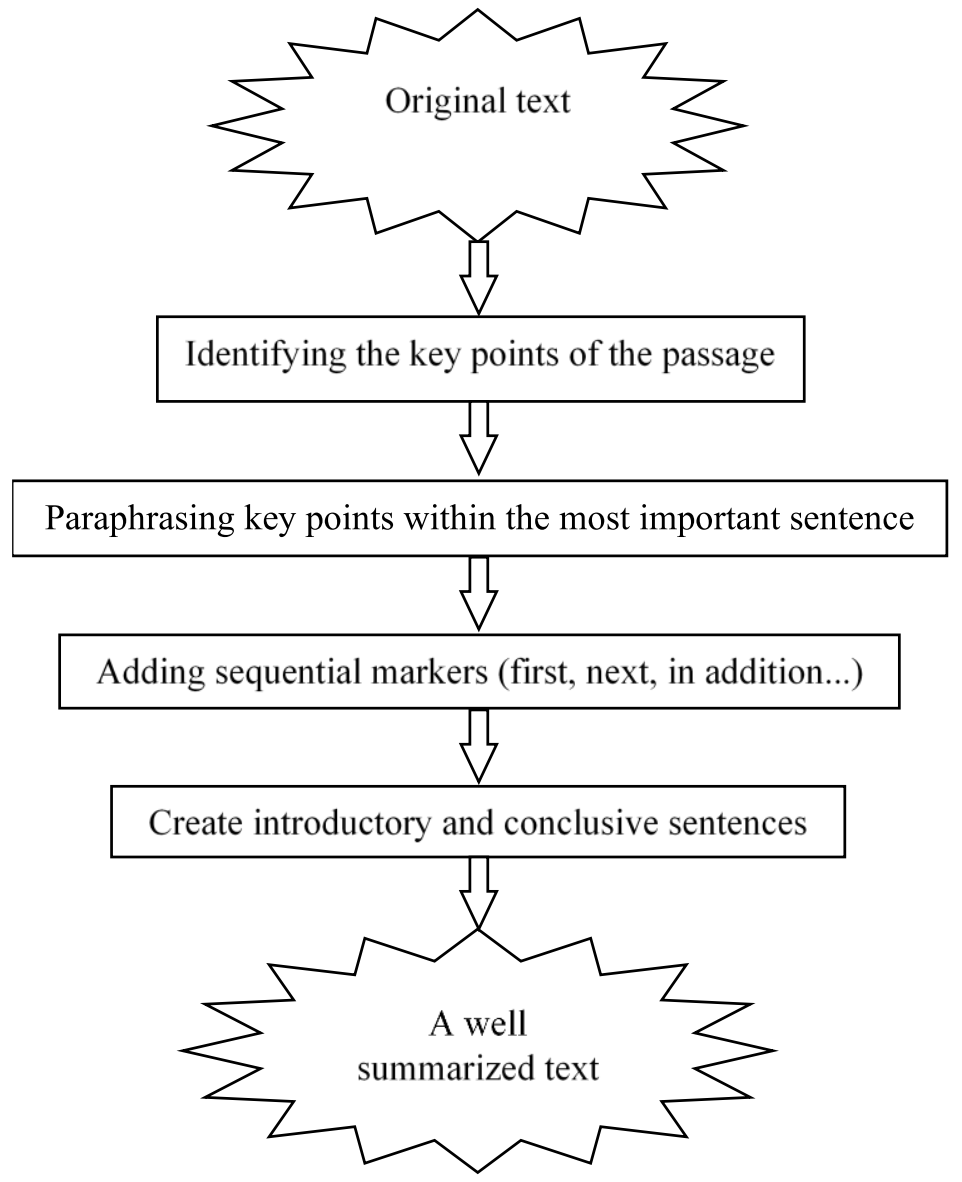

Here are some practical activities to develop summarizing skills:

1) The teacher provides students with a reading material of maximum 3 pages, gives them 10 minutes to go through the text. Then he/she asks them to write out the most important sentences, paraphrase them and add discourse markers to introduce the text in a logical sequence. After that the students write down an opening and a closing sentence.

At the end of the activity the students compare their work with their peers, and discuss advantages and drawbacks in each summary.

2) If the teacher doesn't have much time for the up-mentioned activity, he/she may just divide the lessons into chunks (10-15 minutes), pause and use a summarizing practice about the information just presented during these 10 minutes.

3) Another good activity is as follows;

At the very beginning of the lesson, the teacher introduces the summary of the lesson. At the end of the lesson students are given some minutes to prepare a summary concerning the content of the lesson. Then they compare their summaries with the teachers' summary discussing what they have just learnt. This step will also raise the effectiveness of the lesson.

If we compare summarizing with paraphrasing, we should get the following picture. 

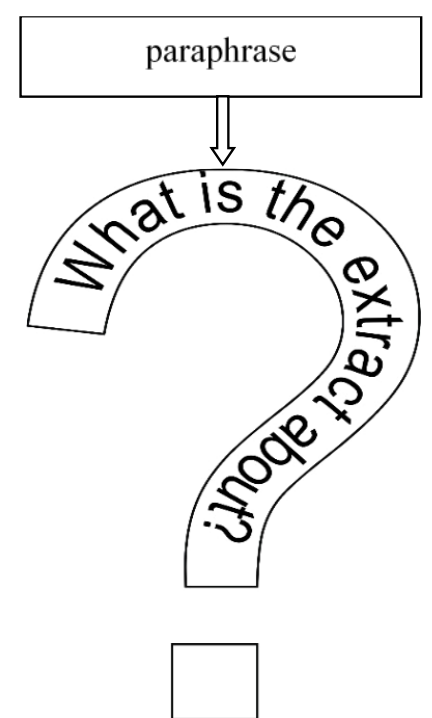

The paraphrased text may be stated longer than the original one. The aim is to clarify the text.
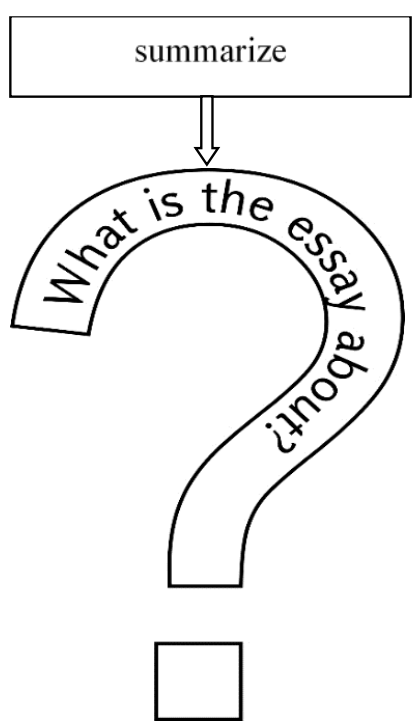

The summarized text in its length must not exceed $25 \%$ of the original text. It aims to give a short description of the text.

To sum up, it should be noted that summarizing and paraphrasing are undeniably important writing skills that are to be practiced and developed through constant and hard work and under the teacher's control.

\section{REFERENCES}

1. Diane Hacker, A Canadian Writer's Reference, Seventh Edition, Canadian edition, 2008, p. 62.

2. Eric Benderoff, Macon Phillips: The man behind the President, Chicago Tribune, February 24 2009, p. 38.

3. Gerald Graff, Cathy Birkenstein. They say/I Say: The moves That Matter in Academic Writing, Gildan Media, $3^{\text {rd }}$ Edition, 2014, p. 31.

4. Gyansah L, Research Journal of Sciences, Engineering and Technology, Maxwell Scientific Publications, Vol.VI, 2010.

5. James Horncastle, BBC, 2018.

6. Joanne Buckley, Fit to Print, Nelson Education Limited 2004, pp. 132-133.

7. Marice Richter, Reuters, 2014.

8. Mendez, The Instrument of Student Judicial Governance, University of North Carolina at Chapel Hill, July 2017 , p. 5.

9. Pechenik, Longman Edition 1,2001, p. 10.

10. Publication Manual of the American Psychological Association, Sixth Edition, 2001, p. 349.

11. Robert J. Marzano and Jane Pollock, Classroom Instruction That Works: Research-Based Strategies for Increasing Student, Assn for Supervision \& Curriculum; 1 edition, January 2001.

12. Seyler D., 1999, Read, Reason, Write, McCraw Hill College, pp. 118-119.

13. Slavkin, The Surgeon General's Report and special-needs patients: a framework for action for children and their caregivers, Volume21, Issue32001, 2001, p. 65.

14. Sousa, How the Brain Learns, 2nd Edition. Corwin Press, 2001, p. 7.

15. Retrieved from https://www.bbc.com/sportfootball/44785173

16. Retrieved from https://www.reuters.com/article/us-usa-police-reconstruction/charging-police-dallasgunman-shows-tactical-skill-in-ambush-idUSKCNOZO2KY

17. Retrieved from https://onlinelibrary.wiley.com/doi/abs/10.1111//1754-4505.2001.tb00232.x 